\title{
Characterization of NiTi Shape Memory Damping Elements designed for Automotive Safety Systems
}

\author{
Joachim Strittmatter, Victor Clipa, Viorel Gheorghita, and Paul Gümpel
}

\author{
(Submitted October 1, 2013; in revised form March 31, 2014; published online May 14, 2014)
}

\begin{abstract}
Actuator elements made of NiTi shape memory material are more and more known in industry because of their unique properties. Due to the martensitic phase change, they can revert to their original shape by heating when subjected to an appropriate treatment. This thermal shape memory effect (SME) can show a significant shape change combined with a considerable force. Therefore such elements can be used to solve many technical tasks in the field of actuating elements and mechatronics and will play an increasing role in the next years, especially within the automotive technology, energy management, power, and mechanical engineering as well as medical technology. Beside this thermal SME, these materials also show a mechanical SME, characterized by a superelastic plateau with reversible elongations in the range of $8 \%$. This behavior is based on the building of stress-induced martensite of loaded austenite material at constant temperature and facilitates a lot of applications especially in the medical field. Both SMEs are attended by energy dissipation during the martensitic phase change. This paper describes the first results obtained on different actuator and superelastic NiTi wires concerning their use as damping elements in automotive safety systems. In a first step, the damping behavior of small $\mathrm{NiTi}$ wires up to $0.5 \mathrm{~mm}$ diameter was examined at testing speeds varying between 0.1 and $50 \mathrm{~mm} / \mathrm{s}$ upon an adapted tensile testing machine. In order to realize higher testing speeds, a drop impact testing machine was designed, which allows testing speeds up to $4000 \mathrm{~mm} / \mathrm{s}$. After introducing this new type of testing machine, the first results of vertical-shock tests of superelastic and electrically activated actuator wires are presented. The characterization of these high dynamic phase change parameters represents the basis for new applications for shape memory damping elements, especially in automotive safety systems.
\end{abstract}

Keywords dynamic testing plant, dynamic tests, Ni-Ti wires, shape memory alloy

\section{Introduction}

Shape memory alloys (SMAs) show unique properties which do not exist in many other materials traditionally used in engineering applications. NiTi alloys are known as the most important SMAs because of their multitude of applications based on the shape memory effect (SME) and superelasticity (SE) (Ref 1-3). These properties are related to the martensiteaustenite and reverse transformation. This is caused by the fact

This article is an invited paper selected from presentations at the International Conference on Shape Memory and Superelastic Technologies 2013, held May 20-24, 2013, in Prague, Czech Republic, and has been expanded from the original presentation.

Joachim Strittmatter and Paul Gümpel, WITg Institut für Werkstoffsystemtechnik Thurgau an der Hochschule Konstanz, Tägerwilen, Switzerland and HTWG KONSTANZ University of Applied Sciences, Konstanz, Germany; Victor Clipa, Coventry University, Coventry, UK and HTWG KONSTANZ University of Applied Sciences, Konstanz, Germany; and Viorel Gheorghita, University Transilvania of Braşov, Brasov, Romania and HTWG KONSTANZ University of Applied Sciences, Konstanz, Germany. Contact e-mails: joker1@htwg-konstanz.de, j.strittmatter@witg.ch and joachim. strittmatter@htwg-konstanz.de. that NiTi alloys have superior properties in ductility, fatigue, corrosion resistance, biocompatibility, and recoverable strain (Ref 1,4$)$ and give the material a large applicability in aerospace (Ref 5) and medical industry (Ref 6) as well as in civil engineering (Ref 7) or automotive industry (Ref 8). The damping capacity consists of dissipating mechanical energy into heat, a characteristic behavior specific not only to SMAs. However, SMAs exhibit a damping capacity that is far greater than the one of standard materials (Ref 9, 10). SMAs have a larger hysteretic deformation and a higher elastic (superelastic) strain compared to conventional alloys and metallic materials (Ref 2). The maximum superelastic strain, $\varepsilon_{\mathrm{s}}$, in such materials can reach $13-16 \%$ (Ref 9-13). SMAs are excellent candidates as dampers or actuators due to their remarkable characteristics, such as high damping performance, high energy dissipation capacity, significant stiffness hardening (variable stiffness), high ductility, long fatigue life, and corrosion resistance capability (Ref 3,14,15). This is linked to the existence of numerous interfaces related to the martensitic transformation: those between austenite and martensite, those between the different variants of martensite, and the twin boundaries inside the martensite itself. In spite of the thermoelastic character of the transformation, many irreversible events occur (production of defects, movement of dislocations, etc.).

SMAs are known for their outstanding capability to absorb mechanical energy and, therefore, to damp mechanical vibrations (Ref 16). NiTi textile elements stretched in tension are expected to show even larger recoverable strains than NiTi wires, thanks to the added geometrical deformation caused by bending and/or twisting of individual wires (Ref 17). Possible 
engineering applications of this pseudoelastic effect include, for example, artificial braided/McKibben pneumatic muscles, releasable energy absorption, impact protection, force control versus strain and temperature, vibration damping, electrical actuation, or sensing capabilities (Ref 12). In addition, this ability to absorb high amounts of energy recommends it for safety systems, such as safety belts and airbag, in the automotive sector (Ref 14). A seat belt (or a safety belt), is a vehicle safety device designed to secure the passenger against harmful movement due to an accident, and keeping him positioned correctly for maximum effectiveness of the airbag (Ref 18). It is evident that road accidents occur within a very short time, depending on the vehicle speed. For this reason the automotive industry is obligated to test their safety devices according to safety regulations that in particular specify the impact speed and the impact energy (Ref 19). In accordance to the automotive safety regulations (Ref 19) in this research will be used the terms "testing speed" or "impact speed" and "impact time", although in the classical field of material science terms like "load time" or "loading rate" are the correct expressions.

This paper aims to investigate the damping characteristics of the tested NiTi SMA wires in the following conditions: different impact energies at different constant temperatures at different high dynamic testing speeds (tested for 3000 and $4000 \mathrm{~mm} / \mathrm{s}$ ).

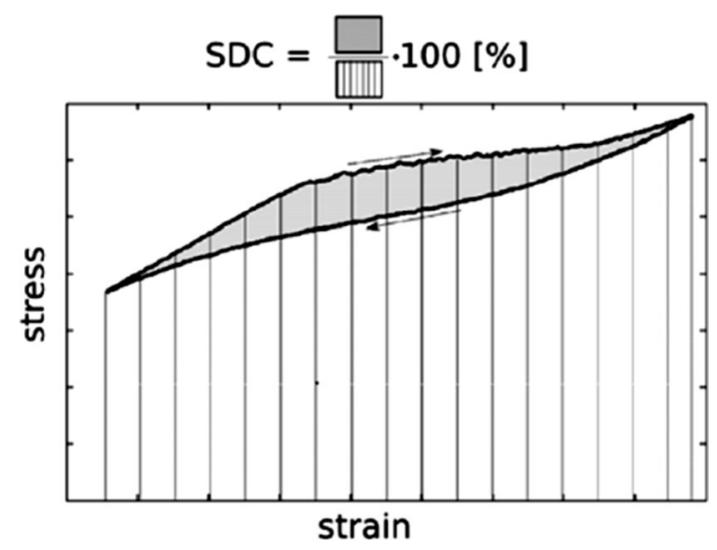

Fig. 1 Damping capacity formula (Ref 12$)$
In this research pseudoelastic wires (in austenite condition) and actuators wires (also in austenite condition) are investigated. For the actuator wires, which have martensitic structure at approximately $23{ }^{\circ} \mathrm{C}$ and austenitic structure at temperatures above $90{ }^{\circ} \mathrm{C}$ (data from SAES-Getters, the supplier of the samples), the phase change process is obtained through Joule's effect, by passing a well-defined electrical current through the wires. Hysteresis observed in SE is one of the energy dissipation manifestations ( $\operatorname{Ref} 2$ ). The area illustrated in the force-displacement diagram (Fig. 1) can be calculated according to the Otzuka and Wayne theory (Ref 20) which is often applied to determinate the specific damping capacity (SDC) (Ref 3, 12).

As shown in the diagram and the equation of Fig. 1 the SDC is defined as the hysteresis area (the area between the graph of the loading and unloading curve) divided through the area under the progression of the loading curve, and therefore is a term in percent $(\%)$. On the other hand, the term $E_{\mathrm{D}}$, the dissipated energy, is used in this research in order to dispose of a quantitative value for the design of new actuators for automotive safety systems. The value of the dissipated energy can be calculated either by using the integration method or the planimetry method.

\section{Testing Methodology}

\subsection{Wire Samples}

During the experiment, several types of SMA wires were used, both actuator and pseudoelastic, with a length of $250 \mathrm{~mm}$ and diameters varying between 0.1 and $0.5 \mathrm{~mm}$. For this reason, each time a different number of wires needed to be tested in parallel, in order to avoid exceeding the stress limit and breaking the wires. The following table shows an example of how many wires had to be used for a specific wire diameter and falling weight (also given as force value in $\mathrm{N}$ ).

For determining the phase transformation temperature, the wires were tested using a differential scanning calorimeter (DSC) under zero stress conditions, at $10^{\circ} \mathrm{K} / \mathrm{min}$. The test results given by the Proteus Thermal Analysis Version 4.1 of

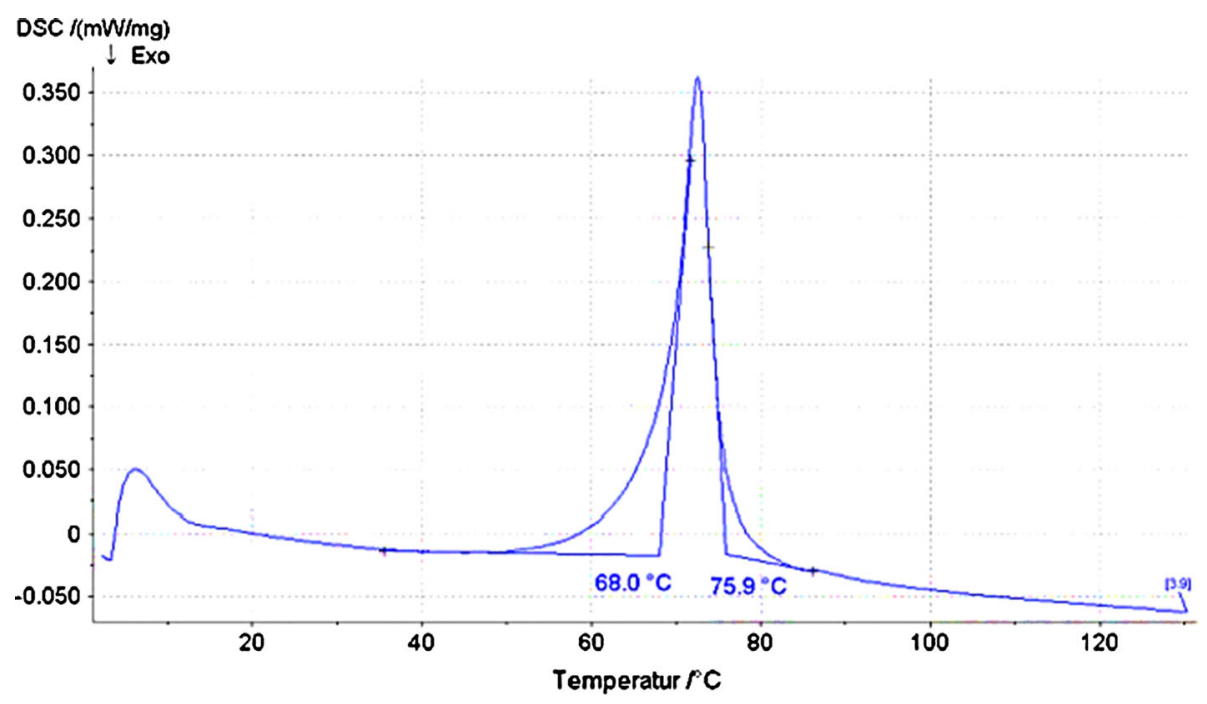

Fig. 2 Differential scanning calorimeter results 


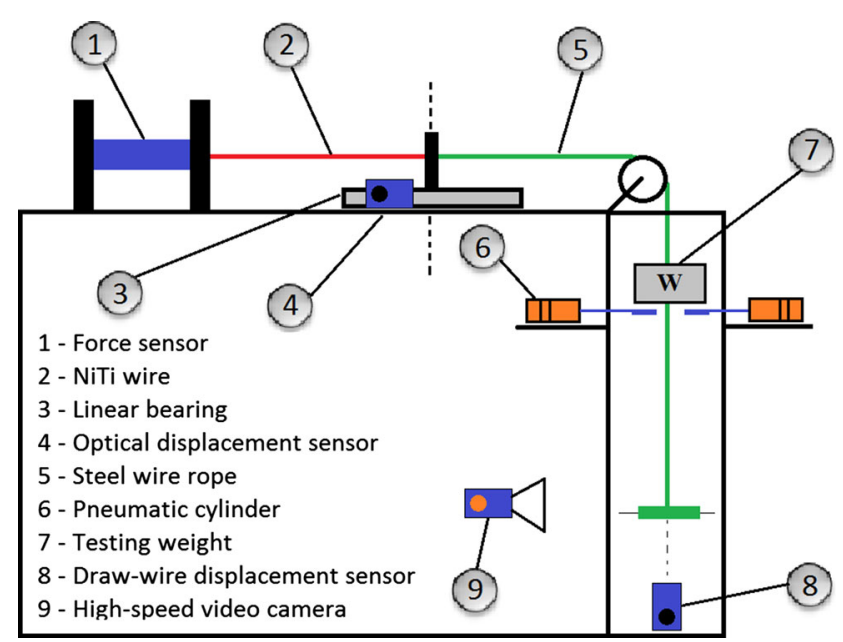

Fig. 3 Drop impact testing machine sketch

the DSC Phoenix 204 testing device are presented in the graph below, indicating the following phase change temperatures: $A_{\mathrm{s}}=68{ }^{\circ} \mathrm{C}$ (austenitic start temperature) and $A_{\mathrm{f}}=75.9^{\circ} \mathrm{C}$ (austenitic finish temperature) (Fig. 2).

\subsection{Testing Equipment}

In literature you may find some testing methodologies and testing plants (Ref 12, 21, 22) to investigate SMAs in the dynamic conditions. These methodologies mainly focus on the application of shape memory damping elements in earthquake protection devices (Ref 23) or vibration damping elements in civil engineering, e.g., bridges (Ref 24). Since the main purpose of these tests was to determine the wires behavior when subject to dynamic conditions close to the crash situation in passenger vehicles, they had to be tested on a device capable of generating enough energy within the meaning of impact energy that suddenly can be discharged on the shape memory samples. Subsequently, this energy would allow a high speed to be obtained, before producing an impact. Moreover, for the actuator wires, the device needed to induce the phase transformation, by changing the wires temperature. This was achieved by including a separate system which activated the memory effect using Joule's effect, by passing an electrical current through the wires. In a real passenger car, this electrical energy could be provided by the car battery (Ref 25).

The drop impact testing machine (Fig. 3) is therefore a testing device used for realizing impact tests, in which the energy is generated by a falling weight. The SMA wire sample is fixed on the machine as follows: one end of the wire is fixed directly to the force sensor and the frame, and the other end is connected to the linear bearing. The force sensor is a piezoelectric load cell of the type 9321B from the company Kistler Instrumente AG, delivered with a calibration certificate according to ISO 17025. The range of measurements goes from 0 till $5 \mathrm{kN}$. For this range the piezo-electric force sensor has an accuracy of $-3689 \mathrm{pC} / \mathrm{N}$. That means for $1 \mathrm{~N}$ the difference for reality is $-3.3683 \times 10^{-12}{ }^{\circ} \mathrm{C}$. This type of sensor is connected to the measuring amplifier Type 5015 from the same company. A displacement sensor is attached to the free component of the linear bearing, to measure the SMA wire elongation/contraction. The assembly also contains steel wire

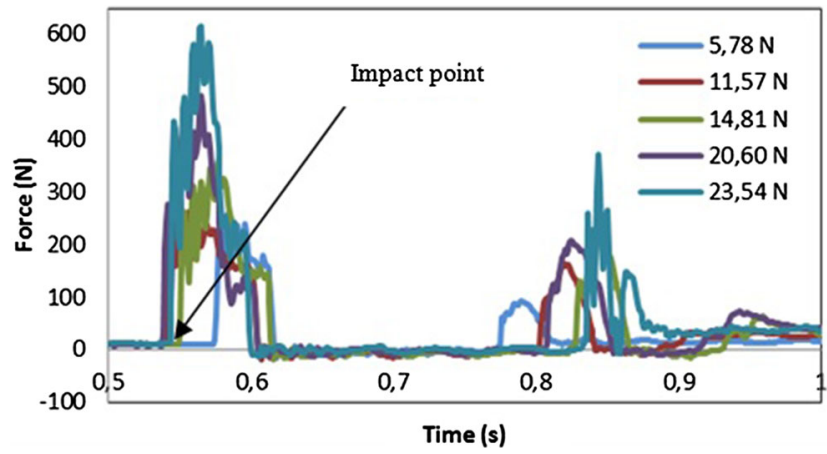

Fig. 4 Force for $0.5 \mathrm{~mm}$ pseudoelastic wires at $v=4000 \mathrm{~mm} / \mathrm{s}$

ropes bent over a set of pulleys and at the end a metal plate is used for impact. A second displacement sensor is fixed, this time to the metal plate. In both positions are used wire rope sensors of the types WDS 300 MP-C-P from the company Micro-Epsilon Messtechnik GmbH \& Co.KG. The accuracy for the measured range $(0$ till $300 \mathrm{~mm})$ is $\leq 0.3 \%$. The falling weight can be controlled by the pneumatic cylinders, opened and closed through a PLC (programmable logic controller). The controlling of the measuring system is realized by LabView using a DataLogger type NI 6210. Work frequency for the measuring circuit was adjusted at $1 \mathrm{kHz}$. This value was selected in accordance with the high speed camera (Motion Extra $\mathrm{N}$ type) which is able to record at maximum resolution $1200 \mathrm{fps}$. In the measuring process for the camera $1000 \mathrm{fps}$ were measured. To protect the measured value from the noises was used a filter (in LabView). Each input signal was filtered from the software.

The main reason for the non-linearity of the graph force versus time (Fig. 4) can probably be found in the connection of the force sensor with the frame of the testing plant (Fig. 3). Because of the accuracy of the force sensor and the falling weight (the falling weight drives through the "preload shaft") it appears vibration which is also recorded. If the values are filtered than the equilibrium for the mechanical energy equation is not valid. Therefore, for future tests are planned to isolate the force sensor from the testing plant frame.

During the initial phase of the test, the weight is in the upper position, which gives it potential energy relatively to the ground. When the two pneumatic cylinders open and the weight is released, its speed will increase, gradually changing the initial potential energy into kinetic energy. This transformation process is followed by the impact with the lower plate, which is directly connected to the SMA wire. An additional behavior occurs when testing the actuator wires: prior to the impact, the electrical current passing through the wires generates heat and induces the phase transformation, causing a significant contraction of the wire. All these rapid changes are recorded with a high speed camera and measurements are logged in LabView using a data logger.

\section{Results and Discussion}

The dynamic experiments were divided into two sets of tests: one at an impact testing speed of $3000 \mathrm{~mm} / \mathrm{s}$ for the 
actuator wires and $3100 \mathrm{~mm} / \mathrm{s}$ for the pseudoelastic ones, and another one at $4000 \mathrm{~mm} / \mathrm{s}$ for both. The small difference between the speeds derives from the construction of the drop impact testing machine. In order to determine a constant stress corresponding to each wire diameter different masses of weight were used as preloads. As these preloads have a variation concerning their diameter-height dimension, the distance of the falling weight and the resultant testing impact speeds were slightly different. The results will be presented with focus on the $0.5 \mathrm{~mm}$ diameter wires.

\subsection{Pseudoelastic Wires}

It is known that NiTi pseudoelastic wires have an austenitic structure at $20{ }^{\circ} \mathrm{C}$, being capable of dissipating a certain amount of mechanical energy. Therefore, the wires were tested with a set of different weights, to observe how their behavior changes in relation with the applied weight. The measurement value of the unfiltered data indicated by the force sensor is initially zero until the impact point, when it suddenly starts to

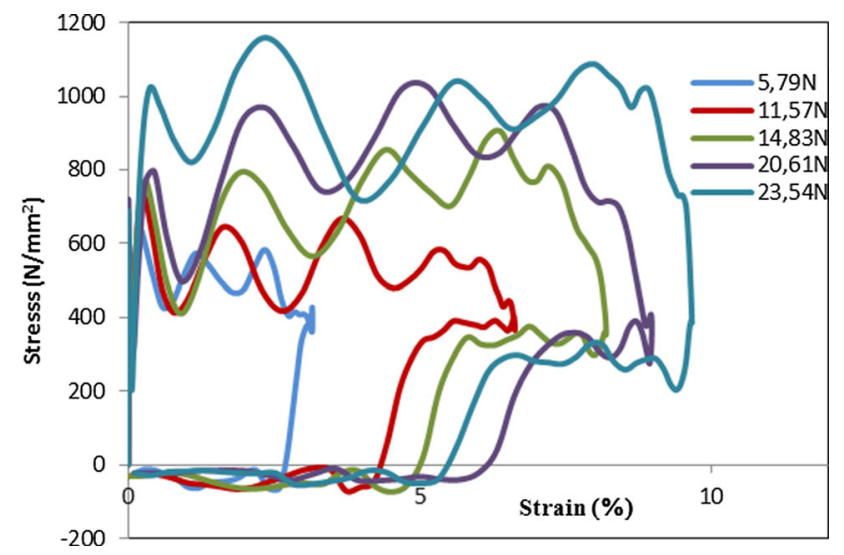

Fig. 5 Stress vs. strain for $0.5 \mathrm{~mm}$ pseudoelastic wires at $v=4000 \mathrm{~mm} / \mathrm{s}$ increase reaching a maximum value, depending on the applied weight (Fig. 4). In the second phase, while the wire returns to its initial length, the graph indicates a decrease of the force values. The following secondary peaks are the result of the oscillations of the weight after the impact, causing an additional stress in the wire. As the highest impact force occurs in the first peak, this region from the impact point till the point when the force is again zero will be further analyzed. This region corresponds to an impact time of less than $0.1 \mathrm{~s}(0.066 \mathrm{~s})$ for the tested maximum conditions (impact speed of $4000 \mathrm{~mm} / \mathrm{s}$ and a falling weight of $2.4 \mathrm{~kg}$ ). As expected, the force values increase proportionally to the mass of the falling weights.

The pseudoelastic behavior of a SMA, associated with stress-induced transformation, can be easily characterized by using a stress versus strain diagram (Fig. 5). Such a graph clearly indicates the strain generation during loading and subsequent strain recovery upon unloading. Furthermore, the area under this curve is an indicator of the energy absorbed by the wire during the impact. This energy is used by the wire to transform itself from austenitic to martensitic structure. The test results indicate that for both speeds, the amount of absorbed energy increases as the mass of the falling weights increases. (Note: the stress versus strain graphs are reduced to a single wire, regardless of the number of wires used for a specific test, i.e., the value recorded by the force sensor was divided by the total number of wires in order to determine the stress value).

Using these graphs, it was possible to quantify the amount of absorbed energy by the wire due to the damping effect. The following table shows the values of the absorbed energy in Joules and also in percentage, which represents the amount of energy relatively to the maximum theoretical energy value (calculated as the area between the upper region of stress versus strain graph and horizontal axis). The results clearly indicate that, for larger weights, the wires absorb more energy and also the impact speed influences the amount of absorbed energy in a positive direction.

In the Table 2, the value of the dissipated energy and SDC are presented, using the values of the force-displacement

Table 1 Number of tested wires in parallel

Dropped weight/force

\begin{tabular}{|c|c|c|c|c|c|}
\hline Specimens (mm) & $0.59 \mathrm{~kg} / 5.78 \mathrm{~N}$ & $1.17 \mathrm{~kg} / 11.57 \mathrm{~N}$ & $1.51 \mathrm{~kg} / 14.81 \mathrm{~N}$ & $2.1 \mathrm{~kg} / 20.60 \mathrm{~N}$ & $2.4 \mathrm{~kg} / 23.54 \mathrm{~N}$ \\
\hline \multicolumn{6}{|c|}{ SMA pseudoelastic wires at $v=3100 \mathrm{~mm} / \mathrm{s}$} \\
\hline 0.15 & 9 & 9 & $\ldots$ & $\ldots$ & $\ldots$ \\
\hline 0.25 & 5 & 5 & 5 & 7 & 7 \\
\hline 0.30 & 3 & 3 & 5 & 5 & 5 \\
\hline 0.50 & 1 & 1 & 1 & 2 & 2 \\
\hline \multicolumn{6}{|c|}{ SMA pseudoelastic wires at $v=4000 \mathrm{~mm} / \mathrm{s}$} \\
\hline 0.15 & 9 & 9 & $\ldots$ & $\ldots$ & $\ldots$ \\
\hline 0.25 & 5 & 5 & 5 & 7 & 7 \\
\hline 0.30 & 3 & 3 & 5 & 5 & 5 \\
\hline 0.50 & 1 & 1 & 1 & 2 & 2 \\
\hline \multicolumn{6}{|c|}{ SMA actuator wires at $v=3000 \mathrm{~mm} / \mathrm{s}$} \\
\hline 0.2 & 7 & 7 & 9 & $\ldots$ & $\ldots$ \\
\hline 0.3 & 3 & 3 & 3 & 5 & 5 \\
\hline 0.5 & 1 & 1 & 1 & 1 & 1 \\
\hline \multicolumn{6}{|c|}{ SMA actuator wires at $v=4000 \mathrm{~mm} / \mathrm{s}$} \\
\hline 0.2 & 7 & 7 & 9 & $\ldots$ & $\ldots$ \\
\hline 0.3 & 3 & 3 & 3 & 5 & 5 \\
\hline 0.5 & 1 & 1 & 1 & 1 & 1 \\
\hline
\end{tabular}




\begin{tabular}{|c|c|c|c|c|c|c|c|}
\hline \multirow[b]{2}{*}{$d, \mathbf{m m}$} & \multirow[b]{2}{*}{$v, \mathbf{m m} / \mathbf{s}$} & \multirow[b]{2}{*}{ Damping } & \multicolumn{5}{|c|}{ Force, N/falling weight, kg } \\
\hline & & & $5.79 / 0.59$ & 11.57/1.18 & $14.81 / 1.51$ & $20.60 / 2.1$ & $23.54 / 2.4$ \\
\hline \multirow[t]{4}{*}{0.5} & 3100 & $E_{\mathrm{D}}, \mathrm{J}$ & 0.935 & 1.59 & 2.97 & 2.99 & 3.9 \\
\hline & & $\mathrm{SDC}, \%$ & 74.9 & 69.86 & 78.81 & 84.02 & 83.01 \\
\hline & 4000 & $E_{\mathrm{D}}, \mathrm{J}$ & 0.75 & 1.44 & 2.41 & 3.29 & 4.28 \\
\hline & & SDC, $\%$ & 82.22 & 78.86 & 82.35 & 87.51 & 88.98 \\
\hline
\end{tabular}

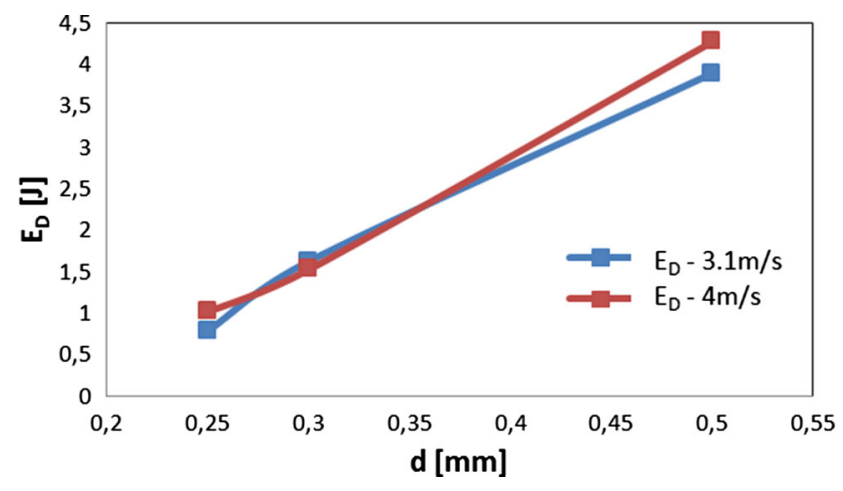

Fig. 6 Diameter influence to the dissipated energy, for the pseudoelastic wires

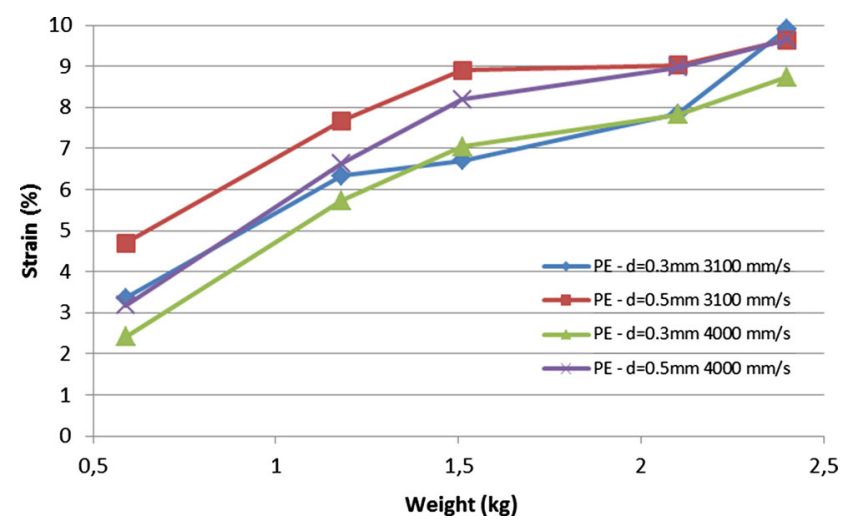

Fig. 7 Maximum strain during impact for pseudoelastic wires

diagrams. The values for the $E_{\mathrm{D}}$ represent the dissipated energy by one pseudoelastic wire. According to Table 1 the whole dissipated energy per test can be determined. In Table 2 it can be observed, that for both testing speeds the damping energy increases when the dropped weight increase. In the same time the damping energy increases linearly with the diameter (Fig. 6). The graph considers the maximum value of the dropping weight for each of the tested wires. Note: in this figure only the test data obtained with the highest load, $2.4 \mathrm{~kg}$, is visualized; for this reason no data of the $0.15 \mathrm{~mm}$ wires is included.

Another interesting aspect of this research was to determine the maximum wire strain immediately after the impact. The strain $\varepsilon$ was calculated as the change in the length of the specimen along the direction of applied load, normalized by the original length. The graph in Fig. 7 suggests that the strain is higher for larger weights and also has slightly higher values for the $0.5 \mathrm{~mm}$ diameter wires.

\subsection{Actuator Wires}

For the actuator wires, a new sequence had to be added in the test procedure, allowing them to go through the phase transformation. By connecting the both ends of the NiTi wire to a power supply and using a timer relay, the wires could be heated using the Joule's effect. During the heating process, the lattice structure changed from martensite to austenite, causing a rapid contraction of the wire and also lifting the lower weight for a short distance. Since previous studies (Ref 26, 27) have shown that $0.6 \mathrm{~s}$ before a car accident is the last time point in which the crash can be prevented, it was important to find out if the actuator wires can be activated in such a short time. Figure 8 confirms that the contraction of the wire takes place in less than $0.6 \mathrm{~s}$ when subjected to appropriate electrical voltage and intensity. Also, the graph indicates that, after the impact, it takes less than $0.6 \mathrm{~s}$ for the wires to dissipate the mechanical energy.

In terms of force values (Fig. 9), the behavior is similar to the pseudoelastic wires, excepting a slight oscillation prior to impact, caused by the contraction of the wires. Then measurement starts to increase reaching a maximum value, depending on the applied weight. In the second phase, while the wire returns to its initial length, the graph indicates a decrease of the force values. The following secondary peaks are the result of the oscillations of the weight after the impact, causing an additional stress in the wire. As expected, the force values increase proportionally to the mass of the falling weights.

For the stress versus strain diagrams (Fig. 10), the actuator wires follow the same trend as the pseudoelastic ones, that means that the area under the curve and therefore the absorbed energy is larger as the applied weight for impact is higher. The tests also indicated that the wires can undergo stresses up to $1100 \mathrm{~N} / \mathrm{mm}^{2}$ at $3000 \mathrm{~mm} / \mathrm{s}$ and up to $1200 \mathrm{~N} / \mathrm{mm}^{2}$ at $4000 \mathrm{~mm} / \mathrm{s}$ without any damage in their internal structure (Fig. 10).

In a similar manner, a table was used to summarize the results for the absorbed energy (Table 3 ). As observed for the pseudoelastic wires, the amount of energy increases when using larger weights. In the same time, the speed of the impact has an influence, increasing the absorbed energy through damping. In comparison to the results of the tested pseudoelastic wires the values of the possible absorbed energy through damping is even higher.

In terms of maximum strain during the impact, the actuator wires have shown that they can exhibit strains up to approx. $11 \%$, especially for the $0.5 \mathrm{~mm}$ diameter wires (Fig. 11). 


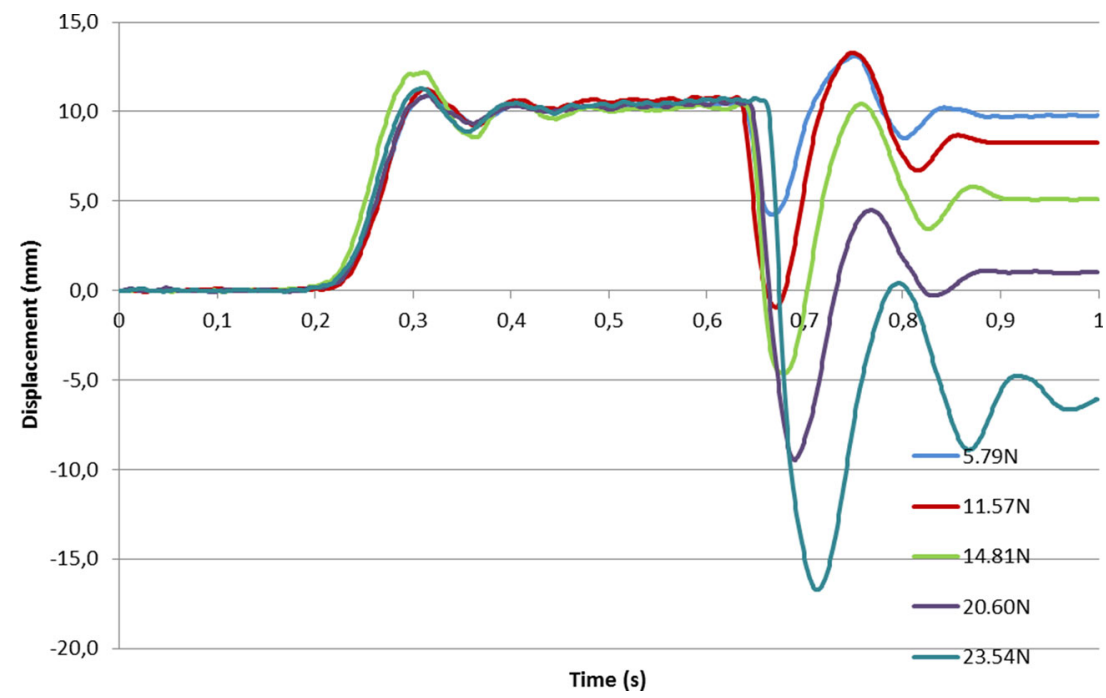

Fig. 8 Displacement for $0.5 \mathrm{~mm}$ actuator wires at $v=3000 \mathrm{~mm} / \mathrm{s}$

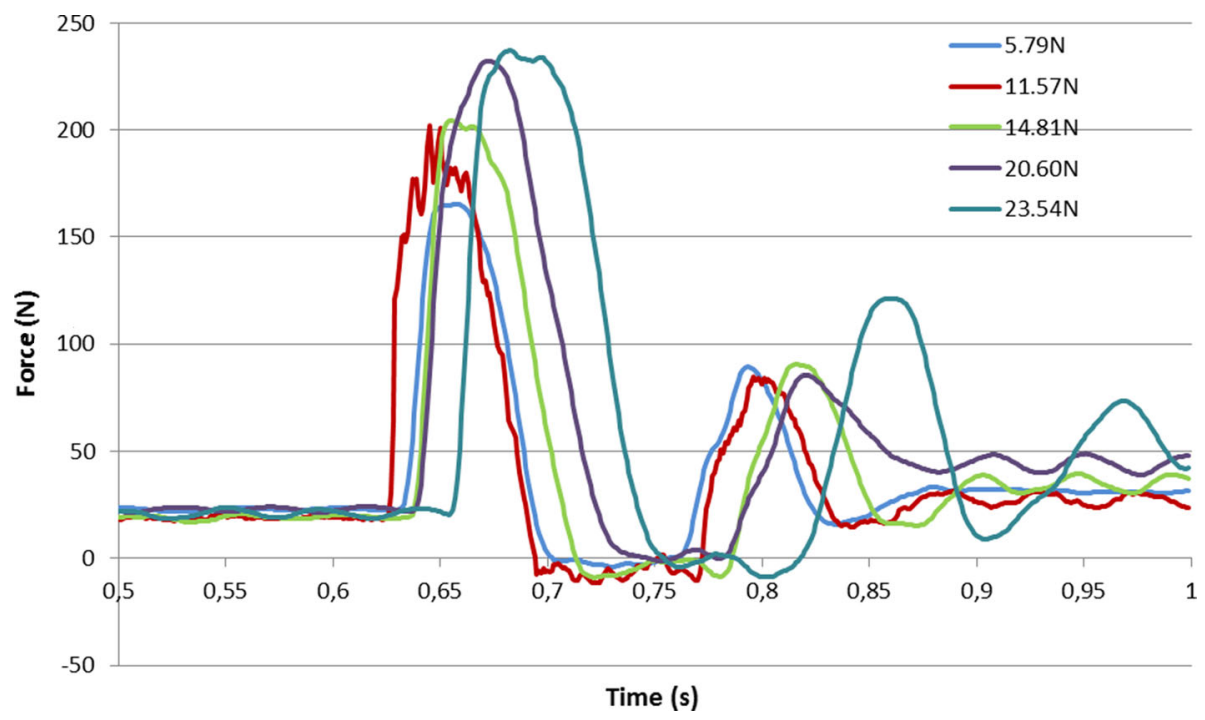

Fig. 9 Force for $0.5 \mathrm{~mm}$ actuator wires at $v=3000 \mathrm{~mm} / \mathrm{s}$

In Fig. 12 it can be observed that the lines of the two different testing speeds are very similar, therefore the different impact speed in this high dynamic condition has a small influence on the $E_{\mathrm{D}}$ value. But this figure shows very clearly the significant influence of the wire diameter on the $E_{\mathrm{D}}$ value, reaching higher damping energies using higher specimen area. At impact testing speeds of $3000 \mathrm{~mm} / \mathrm{s}$ it is found a linear dependency with a strong increasing gradient, whereas at testing speeds of $4000 \mathrm{~mm} / \mathrm{s}$ this dependency is less obvious.

\section{Conclusion}

The first results of this research work show that the NiTi wires are capable of dissipating a significant amount of mechanical energy under dynamic conditions, without damaging the internal structure of the material (indirectly proven by cycle tests, which will be discussed in future publications (Ref 28). This facilitates new possibilities for shape memory damping elements in application, where reversibility and cyclic actuation is required. The test results also indicate that the absorbed energy is higher as the mass of the falling weights increases. When the mass of the dropped load was further increased, some damage in the samples could be detected. This observation feeds the assumption of a limitation when the impact force is increased too much. In addition, the impact speed has a positive influence on the damping capacity of the wire. The actuator wires can be electrically activated in less than $0.6 \mathrm{~s}$, which recommend them in the automotive safety systems industry, especially for a pretensioner device, whose purpose is to tight the slack of a safety belt prior to an impact (Ref 29, 30). Collectively, the test results show, that the amount of dissipated energy increases according to the testing speed and reaches much higher force and 


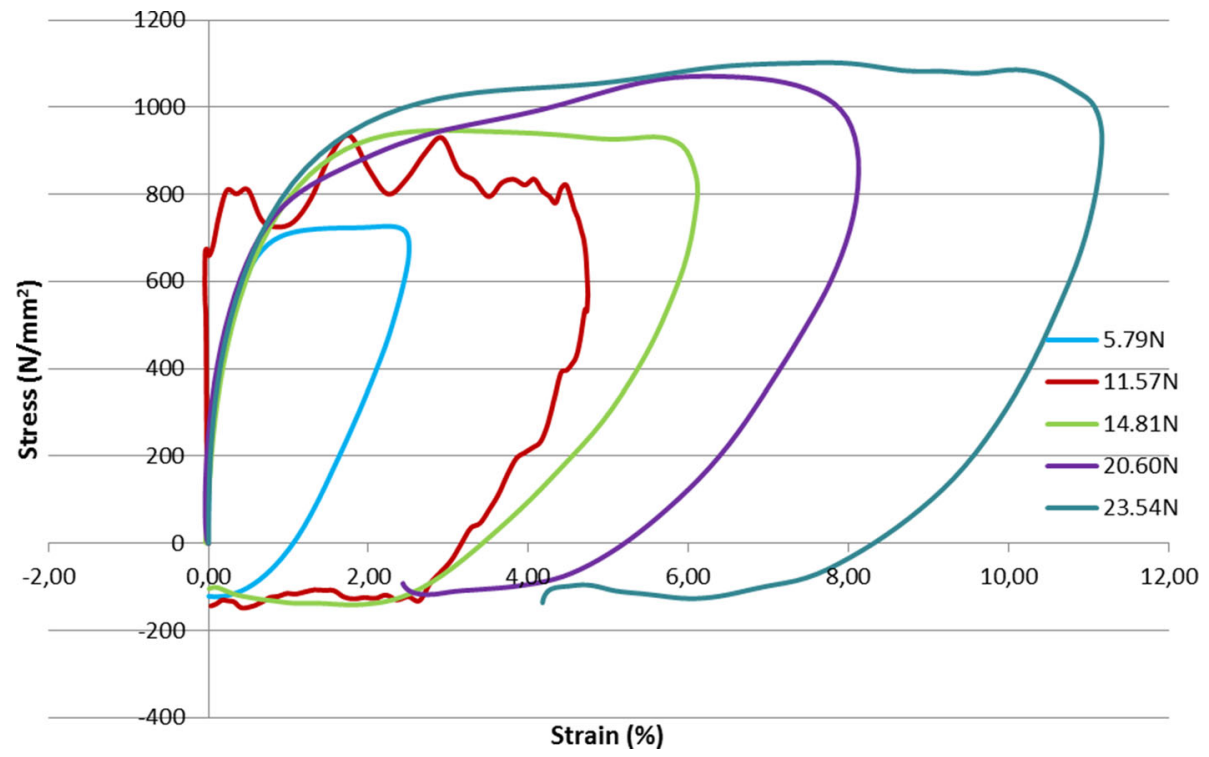

Fig. 10 Stress vs. strain for $0.5 \mathrm{~mm}$ actuator wires at $v=3000 \mathrm{~mm} / \mathrm{s}$

Table 3 Absorbed energy and specific damping capacity value relative to the maximum theoretical value for actuator wires

\begin{tabular}{|c|c|c|c|c|c|c|c|}
\hline \multirow[b]{2}{*}{$d, \mathrm{~mm}$} & \multirow[b]{2}{*}{$v, \mathbf{m m} / \mathbf{s}$} & \multirow[b]{2}{*}{ Damping } & \multicolumn{5}{|c|}{ Force, N/falling weight, kg } \\
\hline & & & $5.79 / 0.59$ & 11.57/1.18 & $14.81 / 1.51$ & $20.60 / 2.1$ & $23.54 / 2.4$ \\
\hline \multirow[t]{4}{*}{0.5} & 3000 & $E_{\mathrm{D}}, \mathrm{J}$ & 0.646 & 1.74 & 2.31 & 3.49 & 5.13 \\
\hline & & $\mathrm{SDC}, \%$ & 59.04 & 94.71 & 82.15 & 84.95 & 90.02 \\
\hline & 4000 & $E_{\mathrm{D}}, \mathrm{J}$ & 0.78 & 1.9 & 2.79 & 4.1 & 5.38 \\
\hline & & $\mathrm{SDC}, \%$ & 95.26 & 93.08 & 95.71 & 95.8 & 95.9 \\
\hline
\end{tabular}

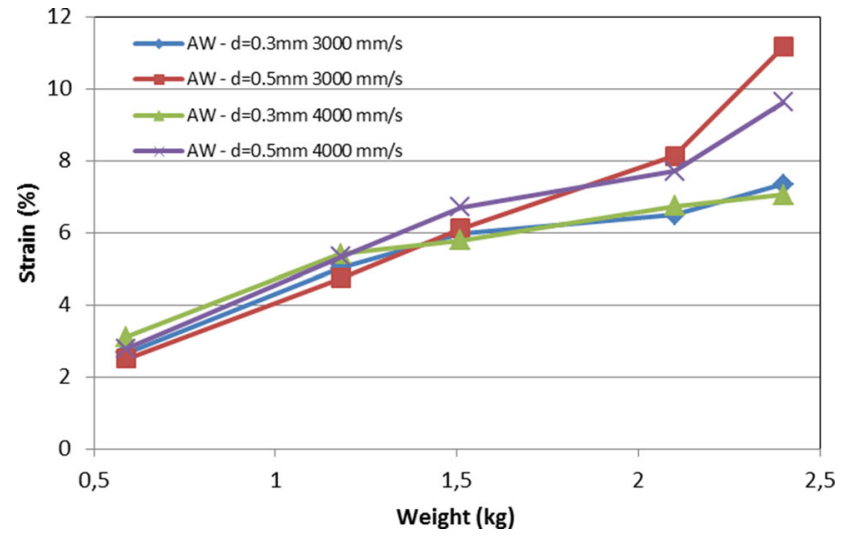

Fig. 11 Maximum strain during impact for actuator wires

deformation values compared to the values obtained in the static tests (Ref 30). The test results show higher achievable values of the damping capacity for the actuator wires in comparison to the pseudoelastic wires. The newly developed drop impact testing machine proved its functionality and reliability; however, for future tests it is recommended to use a more precise force measurement system, which will reduce or eliminate the perturbations. These future tests furthermore will permit testing at higher dynamic impact speeds in order to examine the

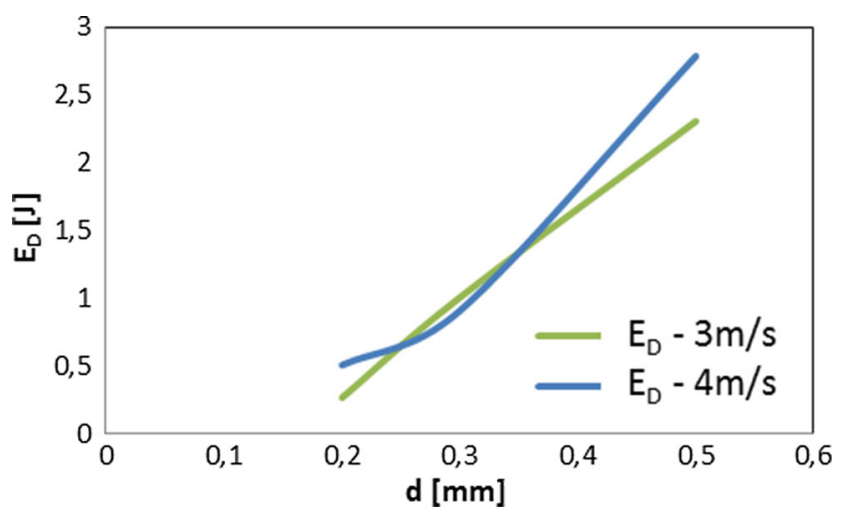

Fig. 12 Diameter influence to the dissipated energy, for the actuator wires

limitations for NiTi specimens concerning their maximum damping capacity without suffering any damage.

\section{References}

1. P. Gümpel, Ed., Formgedächtnislegierungen-Einsatzmöglichkeiten in Maschinenbau, Medizintechnik und Aktuatorik (Shape Memory Alloys-Capabilities in Mechanical Engineering, Medical Engineering and Actuating Elements), Expert, Renningen, 2013, pp 140 (in German) 
2. D.C. Lagoudas, Shape Memory Alloys-Modelling and Engineering Applications, Springer, New York, 2008

3. C. Lexcellant, Shape Memory Alloys-Handbook, Wiley, London, 2013, pp 400

4. S. Casciati, Experimental Studies on the Fatigue Life of Shape Memory Alloy Bars, Smart Struct. Syst., 2010, 6, p 73-85

5. D.J. Hartl and D.C. Lagoudas, Aerospace Application of Shape Memory Alloys, Proc. Inst. Mech. Eng. G. J. Aerosp. Eng., 2007, 221, p 535-551

6. N.B. Morgan, Medical Shape Memory Alloy Applications-The Market and Its Products, Mater. Sci. Eng., 2004, 378, p 16-23

7. M. Dolce and D. Cardone, Mechanical Behaviour of Shape Memory Alloys for Seismic Applications 2. Austenite NiTi Wires Subjected to Tension, Int. J. Mech. Sci., 2011, 43(11), p 2657-2677

8. V. Gheorghita, P. Gümpel, J. Strittmatter, A. Chiru, T. Heitz, M. Senn, Using Shape Memory Alloys in Automotive Safety Systems, Proceedings of the FISITA 2012 World Automotive Congress, Lecture Notes in Electrical Engineering, vol. 195, 2013, p 909-917

9. C. Craciunescu and M. Wuttig, Extraordinary Damping of Ni-Ti Double Layer Films, Thin Solid Films, 2000, 379, p 173-175

10. V.J. Humbeeck, Damping Capacity of Thermoelastic Martensite in Shape Memory Alloys, J. Alloys Compd., 2003, 355, p 58-64

11. J. Honjie, C. Shanshan, K. Changbo, M. Xiao, and Z. Xinping, FineGrained Bulk NiTi Shape Memory Alloy Fabricated by Rapid Solidification Process and Its Mechanical Properties and Damping Performance, J. Mater. Sci. Technol., 2013, 29(9), p 855-862

12. L. Heller, D. Vokoun, P. Sittner, and H. Finckh, 3D Flexible NiTiBraided Elastomer Composites for Smart Structure Applications, Smart Mater. Struct., 2012, 21(4), p 045016

13. Y. Tanaka, Y. Himuro, R. Kainuma, Y. Sotou, T. Omori, and K. Ishida, Ferrous Polycrystalline Shape-Memory Alloy Showing Huge Superelasticity, Science, 2010, 327(5972), p 1488-1490

14. J.M. Jani, M. Leary, A. Subic, M.A. Gibson, A Review of Shape Memory Alloy Research, Applications and Opportunities, Mater. Des., 2014, 36 pp. doi: 10.1016/j.matdes.2013.11.084

15. L. Janke, C. Czaderski, M. Motavalli, and J. Ruth, Applications of Shape Memory Alloys in Civil Engineering Structures-Overview, Limits and New Ideas, Mater. Struct., 2005, 38, p 578-592

16. Y.M. Parulekar, G.R. Reddy, Nonlinear Model of Pseudoelastic Shape Memory Alloy Damper Considering Residual Martensite Strain Effect, Adv. Acoust. Vib., Article ID 231896, 2012, pp 11
17. L. Heller, A. Kujawa, P. Sittner, M. Landa, P. Sedlak, and J. Pilch, Quasistatic and Dynamic Functional Properties of Thin Superelastic NiTi Wires, Eur. Phys. J. Spec. Top., 2008, 158, p 7-15

18. F. Kramer, Passive Sicherheit von Kraftfahrzeugen: Biomechanik-Simulation-Sicherheit im Entwicklungsprozess (Passive Safety of Vehicles: Biomechanics-Simulation-Safety in the Process of Development, 3rd ed., Vieweg+Teubner, Berlin, 2008, 410 pp

19. M. Tideman, R. Bours, H. Li, T. Schultze, T. Nakano, Integrated Simulation Toolset for ADA System Development, Proceedings of the FISITA 2012 World Automotive Congress, Lecture Notes in Electrical Engineering, vol. 200, 2012, p 25-36

20. K. Otzuka and C.M. Wayman, Shape Memory Materials, Cambridge University Press, Cambridge, 1999, 300 pp

21. Y. Chen, H.C. Jiang, S.W. Liu, L.J. Rong, and X.Q. Zhao, Damping Capacity of TiNi-Based Shape Memory Alloys, J. Alloys Compd., 2009, 482, p 151-154

22. R. Lammering and I. Schmidt, Experimental Investigation on the Damping Capacity of NiTi Components, Smart Mater. Struct., 2001, 10, p 853-859

23. G. Magonette, Shape Memory Alloys RF (Reinforce) in Civil Engineering with Particular Regard to Old Structures, Shape Memory Alloys. Advances in Modelling and Applications, F. Auricchio, Ed., International Center for Numerical Methods in Engineering (CIMNE), Barcelona, 2001, p 269-403

24. A.M. Sharabash and O. Andrawes, Application of Shape Memory Alloy Dampers in the Seismic Control of Cable-Stayed Bridges, Eng. Struct., 2009, 31, p 607-616

25. A. Graf, Stromversorgung auf vier Raedern (Electrical Power Supply on Four Wheels), Fachzeitschriften, GmbH, 2006, 14 pp

26. R. Bogenrieder, M. Fehring, R. Bachmann, Pre-Safe in Rear-End Collisions Situations, Daimler AG, Paper Number 09-0129, 2009, pp 8

27. VW Internal Report-Via Vision, Smart Assistance-Safety and Comfort on the Road, 2013, pp 12

28. V. Gheorghita, J. Strittmatter P. Gümpel, A. Chiru, NiTi Alloys Designed for Automotive Safety Systems, accepted for publication in Proc. Fisita World Automot. Congr., 2014, paper F2014-LWS-050

29. K.D. Kusano and H.C. Gabler, Potential Occupant Injury Reduction in Pre-crash System Equipped Vehicles in the Striking Vehicle of Rear End Crashes, Ann. Adv. Automot. Med., 2010, 54, p 203-214

30. V. Gheorghita, P. Gümpel, A. Chiru, J. Strittmatter, Future Applications of Ni-Ti Alloys in Automotive Safety Systems, accepted for publication in Int. J. Automot. Technol., 2014, pp 6 